\title{
Intercultural Communications and Global Social Existence: A cross cultural analysis of communication theory
}

\author{
$\mathrm{a}^{*}$ Leon Miller \\ a. Tallinn University of Technology, Estonia. \\ ${ }^{*}$ Corresponding author's email address: leonmonroemiller@yahoo.com.
}

\section{A R T I C L E I N F O}

Received: 14-09-2015

Accepted: 18-01-2016

Available online: 30-01-2016

\section{Keywords:}

Semiosphere, Architectonic

Methodology, Alterity,

Consummatory, Global-local

dialectics, Complementarity

JEL Classification:

\begin{abstract}
A B S T R A C T
At the mid-point of the second decade of the 21st century humanity is on the verge of another revolutionary advancement and this leap in the progression of civilization is brought about by communication. However, what makes the current revolutionary paradigm shift unique is the extent to which it has created: global-local dialectics, global interdependence, and communication media are contributing to creating multi-levels of global networks that are rapidly advancing civilization to the global level.
\end{abstract}

The shift to the technological age is accompanied by a convergence of global communication media. This convergence is exemplified by media, industries, and human interests (at multi-levels) becoming integrated. This makes a cross-cultural analysis of the semiotic nature of communication and of the impact of media on global social existence essential for creating theoretical insight into the role of media in shaping the future global experience. This article argues that a comparative analysis of the role of communication in shaping culture and the advancement of civilization indicates that the ontological nature of communication reflects a semiotic/dialectic (yin-yang) type dichotomy inherent in the nature of existence that can only be resolved by creating larger spheres of beneficial interactions.

(C) 2015 The Authors. This is an open access article under the terms of the Creative Commons Attribution License 4.0, which allows use, distribution and reproduction in any medium, provided the original work is properly cited.

DOI: http://dx.doi.org/10.18533/rss.v1i1.9

If speculation on the state of reconciliation were permitted, neither the undistinguished unity of subject and object nor their antithetical hostility would be conceivable in it; rather, the communication of what was distinguished. Not until then would the concept of communication, as an objective concept, come into its own. The present one is so infamous because the best there is, the potential of an agreement between people and things, is betrayed to an interchange between subjects according to the requirements of subjective reason. In its proper place, even epistemologically, the relationship of subject and object would lie in the realization of peace among men as well as between men and their Other. Peace is the state of distinctness without domination, with the distinct participating in each other (Theodor Adorno 1985, 498500).

\section{Purpose}

The purpose of this research is to make a cross-cultural analysis of the semiotic nature of communication and the impact of media on global social existence. Such an analysis is essential for gaining insight into the role of media in shaping the future global experience. 


\section{Design}

The research is designed as a conceptual article that undertakes an exploratory investigation into the ontological basis of communications and its impact on social. Such a research design is intended to produce a theoretical explanation of and methodological framework for a scientific investigation into the forces underlying the formation of global social existence.

\section{Findings}

The article reveals that the semiotic/dialectic (yin-yang) type dichotomy inherent in the nature of existence can be resolved by creating larger spheres of beneficial interactions by means of the effective application of communication theory.

\section{The Contribution of this Research to the Literature on Communication}

The article contributes to the body of scientific literature that investigates the role of communication in forces driving the advancement of civilization to the global level. The research also offers a means for offsetting the tendency for Realism to dominate intercultural relations by providing a theoretical model for how interactions and exchanges can result in increased benefits for all participants.

\section{Research limitations}

The research offers a theoretical and methodological framework for analyzing the role of communication in the initiation of culture and the advancement of civilization. However, it claims could be supported with more biological and neurobiological evidence.

\section{Contribution to Science and Future Research}

This research provides insight into how the Realism paradigm that has dominated relations can be informed by inclusiveness on media communication and intercultural communication theories.

\subsection{Introduction}

Historians say that every revolutionary advance of civilization is accompanied by advances in communication. The connection between the printing press and the industrial revolution is an example. Anthropologists add that it was communication that played a primary role in laying the foundation of human culture, the progression of civilization, and plays a role in advancing civilization to the global level. This article argues that an analysis of communication theory reveals the potential that global media have for facilitating the advancement of civilization on to the global level. This article points out that a comparative analysis of communication theory will indicate how the historical dialectic (yin-yang) type dichotomy can be resolved by employing global communication media to create larger spheres of beneficial interactions. The research question is to what extent is media complementary to the ontological forces that progressed culture and civilization to the global level of social existence? In other words do global media facilitate beneficial interactions in domestic social relations, interstate relations, and in the interactions between humans and nature?

This article is a comparative analysis of communication theory and proposes that global communication is a manifestation of a primordial force that impels structuring complex systems and such dynamics have now progressed civilization to a global level of complexity. The article analyzes the connection between inherent human values (ordained by nature's primordial forces), human artifacts (e. g. technology with a special emphasis on information communication technology), and the ontological forces that shape civilization, thus the human value preferences commonly evident in the media. The assumption is that the social, political, and economic values portrayed by the global media reflect something universally basic to human value preferences, the formation of culture, the development of civilization, and to political economy (although each culture reflects this inherent impulse in its own unique way).

This article argues that the ontological basis of collective intentionality sparks human artifacts (e.g. technology) and emphasizes the role that revolutions in communication technology play in the advancement of civilization. Historical examples are: writing, the printing press, the telegraph (the initial global electronic communication devices), and subsequently the ICT revolution. These steps in the development of communication artifacts are 
manifestations of identifiable globally shared values. The aim of the article is to point out the role that global communication media play in the formation of global social existence and, as well, explains the connection between communication and the ontology of social existence.

This research is important because it poses an alternative to the fears held by those believing in Political Realism that there is an inevitable clash between civilizations that is irreconcilable due to the extent of the difference in values (as claimed by Huntingdon, 1993). There are indeed difficult challenges that must be managed because of cultural differences but a transnational scientific inquiry provides a means by which they can be managed more effectively (on the basis of Constructively engaging in communication processes to generate more beneficial human interactions and, as well, establish a Cosmopolitan theoretical framework for how communication media contributes to shaping global social existence).

Because of individual differences analysts will be challenged by conflict. But by viewing the differences from the perspective of Dialectics (as proposed by classical Chinese cultural values stating that what seems to be oppositional is actually complementary) one will be able to maintain respect for the differences. There will be recognition of differences (as with the distinction between yin and yang) but at the same time there will be realization that the differences do not have to be viewed as oppositional but can be perceived as complementary. Reducing conflict can occur when one understands and appreciates the ontological basis for the principle of mutuality (natural law and/or the principles of the natural order) which is the basis for respecting individual uniqueness.

This article is based on the theoretical presupposition that science provides a universally accepted perspective (transcending cultural, ethnic, national, and religious differences). There are indeed differences but there is universal agreement that the claims of naturalism are a reliable basis for gaining justifiable knowledge), do not clash with cultural particularity, thus prove to be a more reliable basis for international discourse. The universality of scientific knowledge, articulated in such a way as to be in line with the perennial or timeless wisdom that is cherished by cultures (grounded in an ontological understanding of the nature of humanness as well as the Philosophy of Science) can be formulated in a way to produce valuable insight that will be appreciated and accepted transculturally.

A good example is the shared belief in a positive correlation between personal and social well-being (as proposed in the Virtue Ethics of both Confucius and Aristotle). That is to say that in spite of the vast cultural differences there is shared social science agreement that humans are social beings that thrive better when self-interest is constrained (which will safeguard the interest of the individual while promoting the common good). This is significant in that the current extent of global interdependence calls for global social science research into: the connection between the common ontological nature of humanness, the ontology of social formation (both domestic and interstate), the nature of the principles that are required for safeguarding the interest of the global public, and how a semiotic perspective on communication theory contributes to a better nature-human relationship.

This article proceeds in the following manner. The second section of the article describes the theoretical framework upon which claims regarding communication are based. This section points out that both Eastern and Western scholars have predicted that the progression of civilization will advance to the global level. Their predictions were accompanied by the realization that the advancement of civilization will necessitate generating scientific knowledge regarding both the role that communication plays in progressing civilization and its role in shaping the global social experience.

The third section describes a methodological approach for a comprehensive analysis of global communication media. This section argues that determining the potential that global media have for enhancing global social existence is achieved by highlighting the complementary connection between Cosmopolitan discourse ethics and the established communication theories of the East and West. Section four draws conclusions about how communication media influence global social existence or, in other words, applies the communication theory outlined in this article to contemporary global social existence.

\subsection{Theoretical framework}

"We found that everything man [kind] makes and does, every procedure, every style, every artefact, every poem, song, painting, gimmick, gadget, theory, technology - every product of human effort - manifested the same dimensions" (McLuhan, 1988, ix). 
Aristotle's views on communication resonate with those of classical China in that his theory proposes that there is a connection between communication and cosmology (meaning that Aristotle suggested that there is a semiotic nature to existence). To accurately describe Aristotle's definition of communication one has to take into account his views concerning biology, ontology, social psychology, political economy, ethics, and epistemology. He defined communication as an interaction, the resulting impression (sensation), and a subsequent interpretation which in the human case is shaped into a conceptualized interpretation of the experience (see his description of energeia in Aristotle, 2009, 125). In a more practical sense he defined communication as a universal form of dialectics where a person uses communication skills to shape encounters into desired outcomes.

"Communication, [also considered as dialectics], is the ability 'to make a way' or to trace a path to be followed which will lead (without unnecessary deviations) to the place at which one wishes to arrive (Aristotle, 2009, 4).

Confucius was one of the first Far Eastern social theorists to develop a model for employing communication strategies in response to the rising social challenges resulting from civilization expanding to the level of conflicting kingdoms/empires. He asserted that to resolve the turmoil — that he recognized as being created from civilization moving beyond tribal-village filial social bonds toward ever expanding empires-he proposed that communication theory must advance in a way aligned with the basic ontology of human nature but amenable to civilization expanding to a larger scale. He believed that the disruption (and the resulting conflict) could be transformed into social harmony (和而不同) by proper use of communication techniques.

Confucius asserted that social media could be employed to promote conceptual clarity regarding how certain principles that are prescribed within his communication strategy could be the basis of the power to create results that are beneficial for those involved various levels of interaction (from tribal to regional). One basic principle he proposed was law based on the natural order一Thien fa, tianli or 天理. His normative principles provide a medium of communication that can facilitate differences. In this sense Confucius believed that the right understanding of communication is the key to reconciling the conflicting interests of tribal-clans and can serve as a tool for facilitating harmony on larger social scales.

World famous Chinese scholar Joseph Needham provided insight into the semiotic nature of Confucian communication theory by analyzing it through the lens of Chu Hsi ( $\mathrm{Zhu} \mathrm{Xi)} \mathrm{-} \mathrm{"The} \mathrm{supreme} \mathrm{synthetic} \mathrm{mind} \mathrm{[of]}$ Chinese history" $(1956,458)$. Needham asserted that the Confucian understanding of the ontological nature of human interactions can be equated to the conceptual claims of contemporary science. In other words Needham compared the Confucian ontological concept of China (i.e., yin-yang), with Gilbert and Volta's understanding of complementarity. Complementarity in contemporary scientific terms means an understanding of how a plus energy force (neutrons - or positive charge) can be in essential harmonious relationship with electrons (negative charge) which reflects the nature of all atomic structures and interactions $(1956,467)$. Needham drew the conclusion that for Confucius the ontological nature of communication is a reflection of the semiotic nature of existence. Needham assumed that Confucius shared the conviction that information encoded into the fabric of existence can be decoded by means of the techniques prescribed in the I Ching.

Basic to the philosophy of the I Ching is the concept of Dialectics which means, "That which appears as contrasting or oppositional is actually complementary" (Miller, 2013, 146). In terms of how the notion of Chinese Dialectics developed-on the basis of the Confucian commentary of the I Ching-Dialectics proposes the possibility that the tension of intercultural interactions (the oppositional forces of thesis and anti- thesis) can result in progressive change (synthesis) depending on the level of transparency of the interlocutors (Chen 2009, 76). Transparency for Confucius can be achieved by communicating on the basis of the I Ching principle of chhêng (真诚) or sincerity which "Denotes more than the usual ethical connotation of the word at the human social level, and indeed has been elevated to the level of a cosmological principle (Needham, 1956, 468).

Confucius was the first to propose that the Taoist-based communication theory establishes a semiotic connection between the essence of being (the information that is encoded into nature) and cognition (the human ability to decode nature's blueprint or the information encoded in natural patterns), thus the human ability to conceptualize the laws of nature by means of communication processes. Confucius develops his theory of human relations based on the claim that the order of existence compels individuals to seek more beneficial interactions. This primordial urge inclines humanity to adhere to its neurobiological make-up which impels acting in accordance with the valuepreference for making interactions beneficial. Li 理 is the means of harmonizing nature's primordial urge with human neural value preferences. Abiding by Confucian communication ethics can result in chhêngor transforming the dialectic tension of chi shan (seeming contrast) into Li 理 (which can be described as social order and harmony with the natural principles of existence) (Needham, 1956, 469). This traditional Chinese concept was the basis of facilitating the shift from tribal-village, to kingdom/empires, nation-states, and currently the possibility for shifting to global social existence. 
In this respect Li means more than ritual in that it is connected with customs that are in accordance with the natural order, natural patterns, or natural law. That is to say that Confucius' ideas were consistent with the Taoist perspective on Virtue Ethics. In Taoist and Confucian philosophies communication can be defined as interaction based on the principle of Li (interaction that brings out the best in human nature) (Chung-Ying, 1987, 30). In other words Chinese dialectics represents the possibility of turning yin-yang tension into outcomes in line with Tao (by means of Confucian communication ethics) (Chan, 1963, 260-263). Thus, the principle of Li is a means for counterbalancing the Realist fear that the outside world is full of potential threats that political, military, and ideological systems provide a safeguard from.

Communication can be defined as an interactive process by which knowledge is generated thus the ontological basis of epistemology. Interaction based on Cosmopolitan principles of engagement empower interlocutors to produce more beneficial outcomes from the interaction (Chung-Ying, 1987, 32). The benefits derived are often described in aesthetic terms similar to those emphasized by Confucius. The classical Chinese perspective, its ontological foundation regarding the nature of existence, the ontology of social existence, and its epistemology influenced European Enlightenment ideals. This influence was especially evident in the philosophy of Gottfried Wilhelm Leibniz and his application of the I Ching principles to the invention of the first computer device.

Leibniz recognized that inherent in the I Ching is a means by which one could understand the ontological basis of knowledge generation (the semiotic basis of how learned behavior can be a basis for complementary interactions and for establishing the foundation of culture). Leibniz explained interaction and communication (along with the technology that facilitates communication) in Taoist terms. He defined communication as a dialectic synthesis of what seems to be oppositional to produce progressive outcomes (communication is the means by which the apparent differences are harmonized to create life-enhancing outcomes) (Leibniz, 2008, xlix-li, 1). Leibniz recognized that the I Ching is not only a source for insight into cosmology, ontology, and epistemology but a perspective on interactions that contributes to reconciling the subject-other dichotomy. Leibniz envisioned that the communication theory inherent in the I Ching could promote "commercia inquam doctrinaeet mutuae lucis" (communication of mutual enlightenment between the Westand China) (Leibniz, 2004, 125).

The belief in achieving A Great Global Harmony (described by Western Liberalism as the potential for Perpetual Peace) was also expressed in the ideas of Sun Yat-sen (known both as the father of China and also as the George Washington of China). Sun Yat-sen was attempting to help China adjust to the demands of the expansion of civilization in a way consistent with its traditional views regarding harmony (with nature-Taoism, within oneself-Buddhism, and within society-Confucianism, thus, creating The Great Harmony). Like Confucius Sun Yat-sen believed that achieving such harmony would be commensurate with obtaining Tian Tao (天道). The Great Harmony Dàtóng (大同), and Tian Tao (天道) are thought of as synonymous in that they both reflect the concept of Minyi (民) - which means ushering in a new era where the inherent nature of the individual is able to manifest in a way consistent with what is best for contemporary society (Lai To Lee, 2011, 315).

There was a corresponding view in the works of pioneering Chinese sociologists. Fei Xiaotong (award winning scholar who studied under the infamous Western scholar Bronislaw Malinowski) held the same view regarding the universality of natural law or appropriately relating to the natural order. Fei Xiaotong's viewpoints concurred with the claim that naturalism is the most reliable method for improving the human condition. He believed that because science is a universally agreed upon perspective on knowledge it is a reliable basis for improving the living conditions of the individual-especially in relationship to the social conditions that the individual is embedded in (as proposed by Confucius and Aristotle). Fei Xiaotong asserted that science plays an effective role in human history when used for meeting the growing need for an ever-better material and social life for the greater majority, and hopefully even for humanity as a whole. He proposed that the desire to restore the dignity of humanity demands upholding a belief in the basic unity in the people's collective life, however diversified its forms may be (Fei, 2002, 140-142).

Fei Xiaotong sensed a need for a new approach to the science of humanity (one that would restore to the so-called subhuman condition true humanity). With his literary talent, combined with his scientific proficiency, he convincingly led his readers to see that there is a unity in people's collective life, regardless of cultural differences. Fei Xiaotong believed that in spite of the differences in individuals and cultures "The basic unity of human social culture is there for all to see and that all nations of the world are bound to achieve common prosperity in the end" (Fei, 2002, 142). He seemed to share in the Western Enlightenment vision that civilization would progress to a point where social scientific knowledge would be applied to building a better world for all of humanity.

The convergence of Eastern and Western philosophical viewpoints (as expressed in the portrayal of Confucianism and evident in the works of Leibniz) was further elaborated on in the West by American Pragmatist John Dewey. 
Dewey's Pragmatism was based on the conviction that communication is a means by which two beings (either social beings or a person in interaction with natural phenomena) form an experience that results in a complementary impression of self and other (reality). The effectiveness of one's communication determines whether or not the interaction can be shaped into satisfactory outcomes. Dewey, like Confucius, regarded communication as the basis of how sensations are turned into conceptualizations and a sense of self (the dialogic self). Thus, according to Dewey, communication is fundamental to how individuals perceive reality, the basis of how conceptualizations of reality are formed, and the basis of social formation (the means by which self-interest is transformed into the common good) (Grange, 2004, xi).

Dewey defined communication as an exchange that has the possibility of creating a consummatory experience where interaction, impression, and the conceptual reaction result in an outcome that one desires (in society and in intercultural relations) thus helps a person to be better integrated within one's world. In Dewey's own words, "Communication realizes [what one wants] at less cost than personal labor exacts since it procures the cooperative assistance of others. Communication-an immediate enhancement of life- procures something wanted [thus] is both instrumental and consummatory. Discourse brings with it the sense of sharing and merging in a whole" (Dewey, 1929, 183-184).

Dewey believed that a semiotic perspective-if developed-enables a person to perceive existence in terms of triadic communication interactions the results of which allows energeia to play a role in the outcome of the encounter (energeia represents the potential encounters have for actualizing what is of intrinsic value). Thus, communication has ontological significance because it is a means by which what is essential for experiencing a harmonic interaction with the natural order and within one's social context becomes the basis of perception, conception, and experience (Dewey, 1929, 183). Dewey described communication as a natural bridge that reconciles the problematic dichotomy between phenomena and noumena. In this sense Dewey asserted that "Of all affairs, communication is the most wonderful" $(1929,166)$. Thus, Dewey stated although critically that the greatest single discovery of humanity was the step out of biological determination by means of social communicative action which was made possible by humanity's capacity to conceptually structure the universe (existence) on the basis of discourse $(1929,172)$.

Dewey's ideas resonate with Confucianism in that he believed that if communication was conducted properly (in line with the Confucian notion of $\mathrm{Li}$ ) the triadic/semiotic nature of existence would be perceived as: The First (Tao or the essence of Being), manifested as The Second (a signal, a communicative act, or an interaction that makes an impression), resulting in the experience of The Third (the interpretant). The semiotic perspective of relational experiences creates a sense of Tao, or a feeling of Holistic well-being). Dewey anticipated-like Confucius-that the semiotic perspective on existence would generate a type of benevolence that would shape one's interpersonal and social experiences. In this respect he regarded communication as the basis of how encounters form conceptualized impressions of the self and the other and how to experience the yin-yang dichotomy as interdependence.

\title{
3.0 Communication and global social existence: A methodological research strategy
}

\begin{abstract}
"For merely because of this permanence do we apply the category of substance to appearance, and people ought to have proved that in all appearances there is in fact something permanent wherein the mutable is nothing but a determination of its existence" (Kant, 1996, 255).
\end{abstract}

The Sociology of Knowledge emerged in the early part of the $20^{\text {th }}$ century as a field of study that investigates the impact that knowledge and power have had on the formation of society and the progression of civilization. Knowledge and power (communication media) are regarded as the means by which power is manifest and exercised over a particular geographical space during a certain period of time (Mannheim, 1954, 50-58). In this respect knowledge (believed to be rooted in accurate insight into the ontological nature of reality) is a reflection of the worldview, ideologies, and political convictions of a society and the basis upon which it has to ability to exercise (expand) its power over a certain region at a particular historical time. However, these convictions inevitably run into conflict when they are confronted with competing knowledge and power claims that represent another social, ethnic, cultural, or political worldview (Mannheim, 1954, 58).

Thus, from the perspective of the Sociology of Knowledge, as civilization progressed and the geographical space that needed to be under political influence expanded communication became a means by which ideological convictions (that are in fact relativistic) and power (that will inevitably clash due to conflicting convictions and interests) can be transformed into relational forms of knowledge and power (for the sake of the progression of civilization and creating larger spheres of beneficial and cooperative interactions). In this respect communication methods became a strategy for determining the means by which the dialectic dynamic of contrasting and 
relativistic convictions can be synthesized into knowledge and power outcomes more beneficial to larger social, economic, and political spheres (Mannheim, 1954, 71-73).

Chung-Ying thought that the most effective method for determining the most effective communication strategies are reflected in the general knowledge, fundamental principles and the underlying assumptions of communication theory. He conceived of communication as an investigation into how humanity (hsing) manages the irresistible urge to interact with some aspect(s) of existence. However, prudence (the human cognitive ability) inclines the individual to transform the tensions arising from the apparent yin-yang (subject-object) dichotomy of the interaction into complementarity (to create outcomes that increase the enjoyment individuals experience in their natural and social world and to reduce discord) (Chung-Ying, 1987, 29). "This also means that this methodology has an ontological aspect, an axiological aspect, a transformational aspect, as well as a Hermeneutic aspect (ChungYing, 1991, 296 \& 306).

Architectonics (the art of turning an aggregate of cognitions into a systematic unity which subsequently turns cognition into science) is also valued as a methodological strategy because it offers a means to critically examine the historical problem of the disparity between what is taken to be discrete and what is perceived as alterity (Kant, 1966, 755). Alterity can be defined as the persistence in viewing reality in terms of a self-other Dualism (the inability to recognize the complementary connection between the self and the other) (Dosse, 1997, 42). Thus, such a Dualistic perspective reduces the possibility of a positive Dialectic exchange between the self and the other. In this respect, communication methodology (when based on Constructivism as a methodological paradigm) is a fundamental approach to researching social relations. Architectonics has long been recognized for its influence on research that uses semiotics as a viable approach to communication and media research (Petrilli, 2013, 89). An architectonic approach to communication theory - an aspect of a semiotic basis for methodology-provides for the possibility of viewing the self-other encounter as the process for transforming dialectic tension into complementarity.

Thus, architectonics is useful as a methodological strategy because of its relationshiop to the semiotic methodological approach that calls for deciphering the coding that occurs in media messages and offers a methodological means for determining meaning. It is based on semiotics insight into how codes reflect something basic to what it means to be human (in addition to their reflecting the signs or symbols of a particular culture). Thus, architectonics (semiotic methodology) is useful for analyzing the use that contemporary mass media makes of the semiosphere to appeal to what could be described as archetypes (the recurrence of symbolic types that appear across cultures as initially proposed by Carl Jung and later by Roland Barthes). Marcel Danesi points out that a semiotic methodological approach is useful because it places emphasis on how global media can potentially have a liberating effect for humanity (Danesi, 2010; 135, 140, \&146).

Methodology, in this sense, is a strategy for applying knowledge, theory, and principles to the yin-yang (dialectic) dynamics of human communication processes so that the flux of reality can be shaped into beneficial outcomes for the individual and societal flourishing for the community. It considers an architectonic strategy for knowledge generation reliable because it is an interdisciplinary approach to research (inclusive of: ontology, epistemology, axiology - research in social and economic value theory, teleology or what has meaning and intrinsic value based on a social psychological perspectives on increasing the experience of what humanity values most, a perspective on how to maximize human well-being, and a political economy approach to increasing the prospects of experiencing the good life).

Architectonics as proposed by one of the most recognized founders of semiotics, Charles Peirce, is a way of researching the complementary connection between what has heretofore persisted in being considered as a disparity $(1891,170)$. Architectonics, in this sense, is a means of synthesizing the knowledge drawn from various disciplines into a strategy for improving social existence. Architectonics refers to a methodological strategy by which knowledge becomes science (or what is considered epistemologically reliable because it is a method by which knowledge becomes demonstrably evident) (Kant, 1996, 255-257).

An Architectonic approach is especially significant as a methodological strategy because it is based on the theoretical value proposition that apparent disparity can be shaped into conceptual unity by means of Cosmopolitan communicative action (as proposed by the Cosmopolitan ethics of Immanuel Kant-one of the major proponents of Architectonics). According to Kant without systematic unity, our knowledge cannot become science; it will be an aggregate but not a system. Thus, architectonic is the doctrine of the scientific aspect of cognition, and therefore necessarily forms part of a viable methodology (Kant, 1996, 755). "By an architectonic I mean the art of systems. Since systematic unity is what first turns common cognition into science, i.e., turns a mere aggregate of cognition into a system, architectonic is the doctrine of what is scientific in our cognition" (Kant, 1996, 755). 
Thus architectonics is a viable methodology for communication research because it provides insight into the formation of human cognition and how knowledge is formed (Boynton, 1996, 94). That is to say that architectonics is the key to an effective analysis of communicative action in that it sheds insight into how cognition systematizes impressions so that they become reliable knowledge. "In the world of human interaction [architectonics] blend the necessities and possibilities of contemporary communication. Architectonics bear a conjunctive relationship in which new possibilities for civic engagement, social movement, and community development sometimes contest and bring to justice systems of excess" (Goodnight, 2014, 2-3 \& 16).

In this respect the methodological approach of this research draws from a the Kantian Cosmopolitan (architectonic) methodological perspective (emphasizing the claim that communication is a means of empowering those participating in a deliberative process - and/or in dialogic interaction-to create knowledge of how to shape interactions into outcomes considered more satisfactory for participants). The hypothesis is that global communication media represent the evolution of humanity's ability to produce knowledge that increases individual well-being, generates more prosperous social systems, increases understanding between the various cultures, and offers a more promising basis for how to collaboratively produce the knowledge necessary for shaping the global social arena in ways that would safeguard the global public. Of course, as those who promote global Contractualism and Critical Theorists point out, this is not without its problems (in connection with whether or not media is merely a means to satisfy the interest of power elite, or is being used to increase commercial advantage, and/or if media is used to promote the political interest of certain special interest groups).

That is to say that the Cosmopolitan methodological approach is useful in this sense because it is inclusive of the Critical Theory critique of the impact of technology on the human experience while, at the same time, placing the emphasis on a Dialogic approach to collaborating to transform the commercial dominance into liberating possibilities. The Cosmopolitan methodology is also very effective in research that involves culture, the relationship between cultures, and analyzing both from the perspective of social psychology. It is compatible with the empirical approach to research but also allows for the interpretive and hermeneutic methods of generating relevant information. In this respect Cosmopolitanism is a method for employing Architectonics to synthesize the vast scope of perspectives that result from interdisciplinary research.

The Architectonic and semiotic methodological approaches offer a basis for making theoretical claims concerning the universality of the human attempt to thrive in spite of the challenges humanity faces from its larger environment. Dialectics, in the Chinese sense, proposes that it is possible that culture and the culture's encounter with things in the world at large can result in complementary interactions. Semiotics proposes a methodological strategy for producing knowledge that makes evident how this is possible (Sebeok, 2001, vii).

In this respect this article is based on the assumption that viable global communication research demands an interdisciplinary research methodological which is the best means for producing knowledge that creates a "highlevel synthesis' in the human sciences and would contribute to managing the growth of interconnectedness that has been evolving over the millennia (what Elias termed as process sociology) (Linklater, 2009, 482). That is to say that research into the role that $21^{\text {st }}$ century global media play in shaping global social existence requires a methodological perspective that integrates what was heretofore claimed to be dichotomous because, in fact, technological advancements in telecommunications have resulted in media becoming an interactive multi-level, multi-dimensional, network of global social discourse.

\subsection{Conclusion: Global media and the formation of global social existence}

"The aesthetic communication alone unites society, because it applies to what is common to all its members" (Shiller 2005 [1974], 94).

The hypothesis of this article is that civilization has advanced to a state that warrants a social science analysis of the intentional collective behavior evident at the global level. A social science analysis is essential in order to make full use of the communication and knowledge generating capabilities that humanity possesses for better managing the conditions and challenges humanity is facing (at the mid-point of the second decade of the $21^{\text {st }}$ century). Unfortunately, there is, as well, evidence of Hard Power forces (political and economic Realism) that are at work to produce threatening or disruptive outcomes to: global security, economics, finance, global social formation, and in terms of how humanity makes use of environmental resources. Thus, there is a need to employ the knowledge and communication technology available to humanity in order to transforms current challenges into satisfactory and beneficial outcomes for the global society. This is especially evident in the fact that the increasing integration of global commercial, financial, media, and knowledge (information) systems makes the global society interdependent. 
Information communication technology has created a communication revolution that is accompanied by an increase in global networking, the integration of international systems, and the convergence of global communication infrastructures. The dramatic changes, taking place at an accelerated pace, are resulting in outdating the traditional theoretical perspectives of international relations, and the methodology for international relations research on global social existence. In this respect this article proposes an interdisciplinary methodology which allows comparing data from research on media, social existence, technology, communication theory, intercultural relations, and the ontology of global social existence.

Renowned Critical Theorist, sociologist, and expert on globalization Anthony Giddens defined social-formation, on the basis of his Structuation Theory, as a communicative engagement that establishes norms (cultural values and worldview) that are shared and could potentially be instituted (by means of the resources that Cosmopolitan engagement enable global agents to generate) into new structures which are produced in the process of engagement by participating agents $(1984,25)$. However, as Giddens pronounced, the impact of globalization is altering the dominance of traditional and national social structures (as the basis for shaping identity and relations) and is resulting in a new and distinct type of social order $(1991,46)$. The developments in technology (information communication technologies) allow for the formation of a sense of identity and social relations that are not bound by proximity (what Giddens calls co-presence). Such new forms of social formation are created by trans-border communication systems which have the power to integrate identities, structures, and systems into a new form of global social interaction $(1984,143-144)$.

As civilization progresses on to the global level analysts realize that one of the greatest challenges humanity faces today is transforming the notion of the so-called anarchic condition of the global arena by means of adopting the Cosmopolitan paradigm for future global social existence. This article argues that the key to effectively responding to this theoretical challenge is in-depth analysis of the relationship between the ontological nature of existence and the role that communication has always played in shaping civilization (especially now with civilization progressing on to the global stage). The concluding section of this article emphasizes the role that aesthetics play in such an analysis. That is to say the role that aesthetics has played throughout the history of the human experience to produce artifacts that enrich culture and contribute to the advancement of civilization (in both Eastern and Western perspectives on artifacts, communication, media, technology, and social formation).

This concluding section argues that the role of aesthetics in shaping human artifacts, culture, civilization and the human experience is made evident in the philosophical perspectives of both Confucius and Dewey. Clarity into the perennial insight that Confucius and Dewey provide enables transforming the seeming anarchic conditions of global relations (intersubjective and intercultural, commercial and economic, and political) into global social harmony is gained by analyzing the understanding that Confucius had of the relationship between the principles of aesthetics and communication theory. Similar insight is gained by analyzing Dewey's views on the relationship between aesthetics, communication, the role that aesthetics play in creating a more enriching human experiences, and the role that aesthetics play as a liberating factor in the human experience (empowers individuals to be able to live the life they prefer/value).

The primary thesis of the article is that communication is the basis of self and social formation (the Socratic revelation-after his visit to Delphi-and, the basic premise of Taoism-that indicates the ontological basis of self-formation plus the connection between communication and the initiation of culture). Confucius drew from the classical Chinese worldview to develop a communication theory that was also based on a complementary connection between the natural order, between the natural surroundings and one's sense of self, and social harmony. He proposed that by molding one's character so that one's ultimate intentions are expressed aesthetically one's inner nature "Works [in accordance with $L i$ ] to achieve a harmonious order that binds society together" (Li, 2010, 19-33).

Confucian expert Roger Ames describes Confucian communication theory as a meliorative agent in the globalizing process because its aestheticism contributes to improving the condition of society (especially in terms of social relations but generally in terms of contributing to a more enriching life) by adding beauty and value to it by cultivating meaningful communication $(2009,259)$. Aesthetics-an important part of the communication process for Confucius-is a feature of communication and interaction that creates $\mathrm{He}$ (Hé 和 harmony) as an outcome. " $\mathrm{He}$ is a social and political process of harmonization in which different and even conflicting views, ideas, or perspectives held by different individuals are resolved by aesthetic ritualism [the art of communication" (Kim, 2014, 61).

This is especially relevant if humanity is to make use of the technologically advanced communication resources available to offset the dominance of the Hobbesian self-other Dualistic view held by those committed to Political and Economic Realism that safeguarding one's interest demands recognizing the threat that the other poses. 
Immanuel Kant, himself, realized that aesthetics was the key to what was holding back the realization of the Enlightenment aims because it would contribute to resolving the problem of Dualism. Dualism has had a strong influence on the anarchic ontological claims of Realism in that it is the basis the skeptic's argument that the human rational/moral capacity is not trustworthy enough to support the claim of Liberalism that mutuality could be the basis interpersonal, social, and interstate relations). Kant proposed that aesthetics establishes a connection between science and reason thus is a means of establishing a complementary connection between the natural order and the human judgment (Kant, 1996, 39-40).

However, as Kant failed to fully develop his aesthetic thesis, American Pragmatists elaborated on his basic argument by stressing that aesthetics contributes to humanity's ability to fulfill its inherent value preference for experiencing complementarity (clarity on the relationship between humanity's ontological nature and the natural order, being better integrated socially and being better-integrated with the natural order) (Guyer, 2003, 159). Dewey envisioned that given the communication capabilities made available by technology (he was especially mindful that electronic communication devices were interconnecting people globally) humanity could remove the barriers holding it back from becoming "The Great Community" (Dewey 2008, 314).

Confucius (accredited with being the first to describe the social significance of aesthetics) like Dewey, thought of aesthetics as the power (a combination of piety, ethics, and prudence) to transform the yin-yang dynamics of encounters into a life enriching outcome (the welfare, happiness, and peace of people) (Hsin, 2006, 160-169). In the communication theory of both Dewey and Confucius adding the aesthetic dynamic to interactions (in both its ethical aspects and in terms of its relationship to enriching and ennobling the human experience) is the means by which individuals are able to fulfill their inherent value preference for creating beneficial outcomes in interactions (what Dewey meant by instrumental experience and what Confucius meant by Wen).

Thus, Chinese classical communication theory (as developed by Confucius) and American Pragmatism (as outlined by Dewey) propose an alternative perspective on the prospects for global social existence. In terms of classical Chinese Philosophy there is, indeed, an emphasis on the Enlightened individual (one who displayed pure conversation or pure speech (Qingtan一清談) which was a Confucian movement that appeared as an effort to deal with social disorder and the expansion of empires to ever larger scales一Xuanxue, 玄学, or 玄學). However such Enlightenment, in Confucian terms, was expressed as a social psychological phenomenon and was intended to create social harmony. Thus, Confucian communication theory was clearly a strategy for helping humanity adjust to the pressures of increasingly larger social spheres. In terms of American Pragmatism the key to creating "The Great Society" lies in understanding the semiotic nature of human interactions, the ontology of social existence, the ontological forces shaping patterns of human communication, and understanding that the socializing forces (that are inherent in the ontological nature of humanity and prompted the development of culture/civilization) are now manifesting at the global level of social existence.

In other words for both Dewey and Confucius during a time of great transition (when there is the tendency to view existence as anarchic) the art of communication has always been the basis of the blueprint for creating social order and harmony (Chan, 2010, 3). In what could be considered China's period(s) of greatest discord Confucian communication principles were considered as the substance and style of a type of communicative action that was admired for its aesthetic appeal and its ability to generate Pure Conversation. The results of which would induce its adherents to succumb to The Mandate of Heaven (an experiential appreciation for and understanding of what it means to be in accordance with Tao) (Xiao, 2002, 138 \& 148).

Dewey believed that aesthetics is the means by which communication theory becomes an aspect of the science of social formation (because it is the basis of how experience and interactions result in consummation-an increase in beneficial outcomes) $(1980,326)$. In fact, as Dewey points out aesthetics has always played a key role in the development of civilization (in economic, cultural/artistic, ideological, and social aspects) in this respect aesthetics contributes to transcending barriers/resistance because it blends together the outlooks of those who otherwise would seem foreign to us and together we consummate the shared social experience (Dewey 1980334 336). In Dewey's own words, communication(s) based on aesthetics (as a form of sincere expression as prescribed by Confucius and as a principle of relational ethics as proposed by Kant) "Is the foundation and source of all activities and relations that are distinctive of internal union of human beings with one another" (1980 335).

Confucius believed that aesthetics is essential because it transforms what would otherwise be a focus on selfinterests or self-preservation ( $A i$, 愛 or the instrumental pursuit for self- gratification) into the fulfillment (or the true satisfaction) of higher order or intrinsic desires (乐一le/lè) (Li, 2010, 12-14). Confucian ethics proposed dūn hòu (敦厚) as an aesthetic concept that enables expressing one's inner nature in ways (similar to Aristotle's claim - outlined in his Virtue Ethics) that increase the ability to gain one's most desired outcome. 
The conclusion of the article has highlighted the role of aesthetics in creating the dynamics necessary for achieving Enlightenment: as the realization of the individual aspiration for experiencing complementarity (for helping the individual to be better-integrated with the natural order and socially-which is an inherent value preference that is ontologically common to humanity). That is to say that Dewey and Confucius proposed that, given the fact that individuals are naturally impelled to enter into relationship, communication became a strategy for producing more beneficial outcomes in the relationship (which meant contracting normative principles). However, rules alone (be they authoritarian, rational/ethical, or religious) are not enough to constrain the individual's natural desires (rules are not enough to harmonize the sensuous and rational aspects of human nature). "The aesthetic communication alone unites society, because it applies to what is common to all its members [thus] demands the co-operation of [the individual's] two natures because it applies to what is common to all [of society's] members" (Schiller 2005 [1974], 94).

In this respect Dewey and Confucius asserted that the aesthetic communication can transform what would otherwise be atomistic individuals, the tendency for there to be disorder in social structures, and an anarchic global arena into a flourishing and prosperity global social existence. Aesthetic communication enables individuals to transform the inherent self-preservation/egotistic and the social forces that what would otherwise tend to disorder and fragmentation into harmonious wholeness. "What is longed for is a sense of wholeness. To be whole is to let difference find its place within the identity of a whole. To be a whole is always to be more than the sum of parts. This "more than" is what powers aesthetic experience. The "more than" characterizing aesthetic experience signifies the ready acceptance of difference into an enlarged form of wholeness" (Grange, 2004, 69).

\section{References}

Adorno, T., (1985) Subject and Object. The Essential Frankfurt School Reader. (Arato, Andrew. \& Gebhardt, Eike. Edits.) New York: The Continuum Publishing Company.

Aristotle. (2009) Aristotle: Rhetoric. (vol 3). Cambridge, UK: Cambridge University Press.

Al-Rodhan, N., \& Stoudmann, G., (2008) Pillars of Globalization. Geneva: Editions Slatkine.

Ames, R., (2009) Becoming Practically Religious: A Deweyan and Confucian Context for Rortian Religiousness. Rorty, Pragmatism, and Confucianism. (Huang, Yong. Edit.). Albany, New York: The State University of New York.

Boynton, G. R. (1996) Our Conversations about Governing. Political Communication Research: Approaches, Studies, Assessments, Volume 2. (Paletz, David. Edit.). Norwood, New Jersey: Ablex Publishing Corporation.

Castells, M., (2008) The New Public Sphere: Global Civil Society, Communication Networks, and Global Governance. The Annals of The American Academy of Political and Social Science. 616, March, 78-93. http://dx.doi.org/10.1177/0002716207311877

Chan, A., (2010) Religion in Early and Medieval China. (Chan, Alan. \& Lo, Yuet-Keung. Edits.). Albany, New York: The State University of New York Press.

Chen, G., (2009) Toward an I Ching Model of Communication. China Media Research. Volume 3, Issue 3, $72-81$.

Chan, W., (1963) A Sourcebook in Chinese Philosophy. Princeton, New Jersey: Princeton University Press.

Comte, A., (2000) The Positive Philosophy of Auguste Comte. (Martineau, Harriet. Trans.). Ontario: Batoche Books.

Chung-Ying, C., (1987) Chinese Philosophy and Contemporary Human Communication Theory. Communication Theory: Eastern and Western Perspectives. San Diago: Harcourt Brace Jovanovich, Publishers.

Chung-Ying, C., (1991) Confucian and Neo Confucian Philosophy. Albany, New York: The State University of New York Press.

Danesi, M., (2010) Semiotics of Media and Culture. The Routledge Companion to Semiotics. (Cobley, Paul. Edit.). London: Routledge Publishing.

Dewey, J., (1980) Art as Experience. New York: Perigee Books.

Dewey, J., (1929) Experience in Nature. London: George Allen \& Unwin, LTD. http://dx.doi.org/10.1037/13377000

Dewey, J., (2008) Later Works Volume 2: 1925-1927. (Boydston, Jo Ann, Edit.). Carbondale, Illinois: Southern Illinois University Press.

Dosse, F., (1997) History of Structuralism: The rising sign, 1945-1966. (Glassman, Deborah. Trans.). Minneapolis, MN: The University of Minnesota Press.

Leibniz, G., (2008) Gottfried Wilhelm Leibniz: The Art of Controversies. (Dascal, Marcelo. Trans. \& Edit.). Dordrecht, The Netherlands.

Giddens, A., (1991) The Consequences of Modernity. Cambridge, UK: Polity Press.

Giddens, A., (1984) The Constitution of Society. Cambridge, UK: Polity Press.

Grange, J., (2004) John Dewey, Confucius, and Global Philosophy. Albany, New York: The State University of New York Press. 
Guyer, P., Beauty, F., and Morality: Kant's Lectures on Anthropology and the Development of His Aesthetic Theory. Essays on Kant's Anthropology. (Jacobs, Brain. Edit.). Cambridge, UK: Cambridge University Press.

Fei, X., (2002) Policy in the Service of Minorities. The Dynamics of Applied Anthropology in the Twentieth Century: The Malinowski Award Papers. (Weaver, Thomas. Edit.). Oklahoma: The Society of Applied Anthropology.

Gunaratne, S., (2005) Public Diplomacy, Global Communication and World Order: An Analysis Based on Theory of Living Systems. Current Sociology. Volume 53, Number 5, 749-772. http://dx.doi.org/10.1177/0011392105055014

Habermas, J., (1976) Communication and the Evolution of Society. (McCarthy, Thomas. Edit.). Boston: Beacon Press.

Hartley, J., (1982) Understanding News Media. Understanding News: Studies in Culture and Communications. (Fiske. John. Edit.). London, Routledge Publishing, viii.

Hsin, K., (2006) Confucian and Western Aesthetics: A Brief Comparative Study. The Pursuit of Comparative Aesthetics. (Hussein, Mazhar. \& Wilkinson, Robert. Edits.). England: Ashgate Publishing Limited.

Huntington, S., (1996) The Clash of Civilizations and the Remaking of the World Order. New York: Simon and Schuster Publishers, 22.

Kant, I., (1996) Critique of Pure Reason. (Pluhar, Werner. Trans.). Indianapolis: Hackett Publishing Company, Inc.

Kim, S., (2014) Confucian Democracy in East Asia. New York: Cambridge University Press. http://dx.doi.org/10.1017/cbo9781107273672

Lai T. L, Hock G. L., (2011) Sun Yat-Sen, Nanyang, and the 1911 Revolution. Singapore: ISEAS Publications.

Leibniz, G., (2004) Leibniz Correspondence with Giovanni Laureati, Rome, November 12, 1689. Leibniz and China: A Correspondence of Light (Perkins, Franklin. Author). Cambridge, UK: Cambridge University Press.

Li, Z., (2010) The Chinese Aesthetic Tradition. (Samei, Maija. Trans.). Hawai'i: The University of Hawai'i Press.

Linklater, A., (2009) Human Interconnectedness. International Relations. Volume 23, Number 3, 482 (Linklater is paraphrasing Elias 2007, 142 \& 152).

Mannheim, K., (1954) Ideology and Utopia: An Introduction to the Sociology of Knowledge. New York: Harcourt, Brace \& Co., Inc.

McLuhan, M., \& McLuhan, E., (1988) Laws of Media: The New Science. Toronto: University of Toronto Press.

Needham, J., (1956) Science and Civilization in China. (volume 2). Cambridge, UK: Cambridge University Press.

Miller, L., (2013) Complementarity, Pragmatism, and Resolving Western Civilization's Continental Divide. Sociology of Science and Technology. Volume 4, Number 4, 144-160.

Peirce, C., (1891) The Architecture of Theories. The Monist. Volume 1, Number 2, 161-176. http://dx.doi.org/10.5840/monist18911211

Petrilli, S., (2013) The Self as a Sign, the World, and the Other. Living Semiotics. New Brunswick, New Jersey: Transaction Publishers.

Ray, L., (2007) Globalization and Everyday Life: the new sociology. Oxon, UK: Routledge Publishing. http://dx.doi.org/10.4324/9780203463345

Sebeok, T. A. (2001) Global Semiotics. Bloomington, Indiana: Indiana University Press.

Shiller, F., (2005) Letter Upon the Aesthetic Education of Man. Raleigh, North Carolina: Hayes Barton Press Publisher.

Xiao, X., (2002) The Rhetorical Construction of the Discourse on the Dao in Daode jing. Intercultural Communication Studies XI-1, 137-151. 